\title{
Comments on Levic et al.: The outcome of rectal cancer after early salvage TME following TEM compared with primary TME: a case-matched study
}

\author{
M. Mistrangelo $\cdot$ M. E. Allaix $\cdot$ A. Arezzo $\cdot$ M. Morino
}

Received: 13 September 2013/Accepted: 14 October 2013/Published online: 1 November 2013

(C) Springer-Verlag Italia 2013

We have read with great interest the recent paper by Levic et al. [1], who compared, in a case-matched study, the outcomes of patients undergoing early salvage total mesorectal excision (TME) following transanal endoscopic microsurgery (TEM) or primary TME for rectal cancer. They concluded that in selected patients, TEM can be chosen as a primary treatment modality, since subsequent abdominal rectal resection combined with TME did not compromise the outcome.

TEM alone is an effective surgical treatment for T1 sm1 rectal cancers only [2, 3], while TEM following neoadjuvant chemoradiation could be considered for more advanced rectal cancer [4]. However, Levic and colleagues included in their analysis both early (stage I) and locally advanced rectal cancers (stage II) that were treated with curative intent by TEM without neoadjuvant treatment. The interpretation of the results presented by the authors is biased by the fact that the groups were matched according to several variables, including the type of surgery performed, and therefore, the risk of abdominoperineal resection (APR) after failure of transanal local excision for rectal cancer, as reported in the literature, was underestimated. Recently, our group [5] clearly stated that

An authors' reply to this comment is available at doi:10.1007/s10151013-1083-y.

M. Mistrangelo - M. E. Allaix - A. Arezzo - M. Morino Digestive and Colorectal Surgical Department, Centre of Minimal Invasive Surgery, Città della Salute e della Scienza Hospital, University of Turin, Cso A.M. Dogliotti 14, 10126 Turin, Italy

M. Mistrangelo ( $\square)$

Via Carlo Alberto Dalla Chiesa 1/R, 10040 Volvera, TO, Italy

e-mail: mistrangelo@katamail.com laparoscopic TME after TEM is associated with a significantly higher risk of APR than primary TME. A full thickness TEM causes the development of a fibrotic scar, making the dissection of the correct planes down to the pelvic floor much more challenging even under clear and magnified laparoscopic vision, and sometimes making a low colorectal or a transanal coloanal anastomosis technically impossible.

Further, large prospective series are needed to evaluate the risk of APR in selected rectal cancer patients treated with salvage TME in case of failure of transanal local excision (i.e., TEM).

Conflict of interest None.

\section{References}

1. Levic K, Bulut O, Hesselfeldt P, Bülow S (2013) The outcome of rectal cancer after early salvage TME following TEM compared with primary TME: a case-matched study. Tech Coloproctol 17:397-403. doi:10.1007/s10151-012-0950-2

2. Koebrugge B, Bosscha K, Ernst MF (2009) TEM for local excision of rectal lesions: is there a learning curve? Dig Surg 26:372-377

3. Morino M, Allaix ME, Caldart M, Scozzari G, Arezzo A (2011) Risk factors for recurrence after transanal endoscopic microsurgery for rectal malignant neoplasm. Surg Endosc 25:3683-3690

4. Lezoche E, Baldarelli M, Lezoche G, Paganini AM, Gesuita R, Guerrieri M (2012) Randomized clinical trial of endoluminal locoregional resection versus laparoscopic total mesorectal excision for T2 rectal cancer after neoadjuvant therapy. Br J Surg 99:1211-1218

5. Morino M, Allaix ME, Arolfo S, Arezzo A (2013) Previous transanal endoscopic microsurgery for rectal cancer represents a risk factor for an increased abdominoperineal resection rate. Surg Endosc 27:3315-3321 